\title{
Are individuals with orofacial pain more prone to psychological distress during the COVID-19 pandemic?
}

\author{
Maryam Saki ${ }^{1, A-F}$, Maryam Shadmanpour ${ }^{2, A-F}$, Hooman Zarif Najafi ${ }^{2, A-F}$ \\ ${ }^{1}$ Health System Research Center, Shiraz University of Medical Sciences, Iran \\ ${ }^{2}$ Orthodontic Research Center, Department of Orthodontics, School of Dentistry, Shiraz University of Medical Sciences, Iran \\ A - research concept and design; $\mathrm{B}$ - collection and/or assembly of data; $\mathrm{C}$ - data analysis and interpretation; \\ $\mathrm{D}$ - writing the article; $\mathrm{E}$ - critical revision of the article; $\mathrm{F}$ - final approval of the article
}

Address for correspondence

Hooman Zarif Najafi

E-mail: zarifhooman@gmail.com

Funding sources

Vice-Chancellor of Shiraz University of Medical Sciences, Iran

Conflict of interest

None declared

Acknowledgements

The authors are grateful to the Vice-Chancellor of Shiraz University of Medical Sciences in Iran for supporting this research (grant No. 99-22701). The authors would like to thank Dr. M. Vosoughi from the Dental Research Development Center of Shiraz Dental School for the statistical analysis.

Received on September 22, 2020

Reviewed on November 24, 2020

Accepted on December 15, 2020

Published online on March 31, 202

\begin{abstract}
Background. It is of utmost importance to identify and treat groups susceptible to psychological problems during the coronavirus disease 2019 (COVID-19) pandemic.

Objectives. This study aimed to compare the psychological status between the general population and subjects with orofacial pain (OFP) during the COVID-19 pandemic.

Material and methods. A total of 509 young adults were recruited based on the inclusion and exclusion criteria, using the convenient sampling approach. They were assigned to 2 study groups: group 1 - individuals with OFP; and group 2 - the general population. Their background variables, knowledge, perception, attitude, concerns, and Kessler scale scores were recorded through an online questionnaire. Student's $t$ test, the $x^{2}$ test, Pearson's correlation coefficient, and one-way analysis of variance (ANOVA) were used for the statistical analysis.

Results. Some of the background variables were significantly different between the study groups $(p<0.05)$. The knowledge, perception and attitude scores of the respondents were not significantly different between the study groups $(p>0.05)$. Females exhibited significantly higher adjusted Kessler scores as compared to males $(p<0.05)$. Group 1 exhibited the highest adjusted Kessler scores $(p<0.05)$.

Conclusions. Individuals with OFP exhibited higher psychological distress, depressive symptoms and anxiety during the rapid rise of the COVID-19 outbreak, representing a moderate psychological disorder. Females suffered more from psychological distress as compared to males. Therefore, psychological interventions should be focused on this group.
\end{abstract}

Key words: psychological status, orofacial pain, COVID-19, Kessler scale (K10)
Cite as

Saki M, Shadmanpour M, Zarif Najafi H. Are individuals with orofacial pain more prone to psychological distress during the COVID-19 pandemic? Dent Med Probl. 2021;58(1):17-25. doi:10.17219/dmp/131683

DOI

$10.17219 / \mathrm{dmp} / 131683$

Copyright

๑ 2021 by Wroclaw Medical University

This is an article distributed under the terms of the

Creative Commons Attribution 3.0 Unported License (CC BY 3.0)

(https://creativecommons.org/licenses/by/3.0/). 


\section{Introduction}

The deadly coronavirus disease 2019 (COVID-19) has promptly become a pandemic with its high transmissibility. ${ }^{1,2}$ The COVID-19 pandemic has adversely affected the mental health of health professionals, patients and the public, increasing the incidence of psychological crises. ${ }^{3-6}$ Symptoms of adverse psychiatric outcomes have become more prevalent in different populations as compared to the era before the pandemic. Currently, varying degrees of the outbreak severity, national economy, government preparedness, the availability of medical supplies/facilities, and a proper dissemination of COVID-related information have led to regional differences in the general public's psychological health. At the beginning of the outbreak, when individuals were challenged by mandatory quarantine, unexpected unemployment and uncertainty associated with the outbreak, symptoms of adverse psychological outcomes were more commonly observed. ${ }^{7}$

Conditions in which an examination by the physician puts individuals at risk of contracting coronavirus disease might predispose them to psychological problems. ${ }^{8}$ One of these conditions is orofacial pain (OFP), with a prevalence of $10-15 \%$ in the adult population. ${ }^{9}$ After back, neck and knee pain, OFP is one of the most common causes of chronic pain. ${ }^{9}$ Recently, it is comprehensively classified as OFP attributed to dentoalveolar disorders and anatomically related structures, myofascial OFP, temporomandibular joint (TMJ) pain, OFP attributed to the lesions or diseases of the cranial nerves, OFP resembling the presentations of primary headaches, and idiopathic OFP. ${ }^{10}$ Acute pain in the orofacial area is often toothrelated. ${ }^{9}$ Chronicity in OFP is defined as pain occurring on more than 15 days per month and lasting for more than 4 hours daily for at least 3 months. ${ }^{10}$ Chronic OFP is most commonly related to musculoskeletal disorders and temporomandibular disorders (TMDs). ${ }^{9}$ Temporomandibular disorders is an umbrella term embracing pain and dysfunction that involves the masticatory muscles, TMJ and associated structures. ${ }^{9}$ Apart from imposing a substantial economic burden on societies, ${ }^{11}$ persistent OFP exerts a great impact on patients' quality of life. ${ }^{12}$ It has been suggested that, both as a confounder and a mediator, psychological distress coexists with chronic pain, and being exposed to pain might exacerbate a depressive state. ${ }^{13}$ Comorbid psychological distress and psychosocial dysfunction have been observed in people with OFP, especially when the pain is chronic, such as in TMDs. ${ }^{14-17}$ A study from 2005 on the presence and impact of posttraumatic stress disorder (PTSD) in a sample of patients seeking OFP treatment suggested that PTSD was prevalent in the OFP setting. ${ }^{18}$ In the era of the COVID-19 pandemic, patients with OFP might even suffer more from psychological distress, as the disease, the lockdown of cities and the associated sequelae have increased the incidence of psychological crises in the whole world population. ${ }^{3-6}$

Psychological factors associated with the pandemic might even lead to a greater risk of developing and perpetuating bruxism and TMDs. ${ }^{19}$ Also, depressive symptoms can influence the treatment outcome of OFP. ${ }^{13,20}$ Therefore, the early identification of the populations in the first stages of a psychological crisis would allow for the efficient implementation of interventional strategies. ${ }^{3}$ Clinicians would devise appropriate measures, including suggestions for professional psychological consultation and prioritizing the vulnerable patients for treatment. To the best of our knowledge, no study has compared the psychological status of individuals with OFP and the general population under the added psychosocial burden imposed by the COVID-19 pandemic. Therefore, this study aimed to compare the psychological distress, symptoms of depression and anxiety in the general population and individuals suffering from OFP during the COVID-19 pandemic. Moreover, the knowledge, perception, attitude, and concerns were compared between the groups.

\section{Methods}

\section{Subjects}

The study was conducted in Shiraz, Iran. Individuals aged 19-39 years were recruited in this study. The convenient consecutive sampling approach was used. Individuals with past or current neurologic or psychiatric illnesses or systemic diseases, or any oral and maxillofacial surgeries or orthodontic treatment in their treatment plan were excluded by asking the inviters not to invite them to participate in the study and ensure it with similar questions in the questionnaire. The respondents were divided into 2 groups as follows:

- group 1 - patients suffering from chronic pain in the orofacial region for more than the last 3 months, diagnosed by the clinicians through history, physical examinations and validated pain questionnaires (Brief Pain Inventory, Beck Depression Inventory, Hospital Anxiety and Depression Scale, McGill Pain Questionnaire, and Oral Impact on Daily Performance). The records and documents of the patients, from the date of the announcement of the beginning of the pandemic (March 11, 2020) to April 11, 2020, in 3 pain clinics and 3 dental emergency centers, were searched, and eligible subjects were invited to fill in the questionnaire. The same administrator was introduced to all the patients via a phone call by the clinic. The nature and purpose of the research were explained to the patients by the administrator through the WhatsApp messenger. The patients were allowed to ask the administrator questions via the messenger; 
- group 2 - the general population with no diagnosis of OFP. The general population was invited to participate in the study through social media, including Instagram accounts, WhatsApp groups or Telegram channels, with more than 1,000 followers.

\section{Ethical considerations}

The protocol of this cross-sectional study was approved by the Ethics Committee of the Vice-Chancellor for Research at Shiraz University of Medical Sciences in Iran (No. IR.SUMS.DENTAL.REC.1399.122). The participants were told about the nature and purpose of the research by 1 administrator. The participants were allowed to ask the administrator questions through the WhatsApp messenger. They were reassured that all their personal data would be kept confidential. Informed consent was obtained from all the participants.

\section{Questionnaire}

The questionnaire consisted of 3 sections (Fig. 1).

The $1^{\text {st }}$ section focused on individual background information and the person's primary source of information about COVID-19. Questions regarded the current orthodontic treatment, the current OFP and its treatment, and 6 questions related to the probability of catching coronavirus, job closure and quarantine. Questions about the exclusion criteria were also asked in this section.

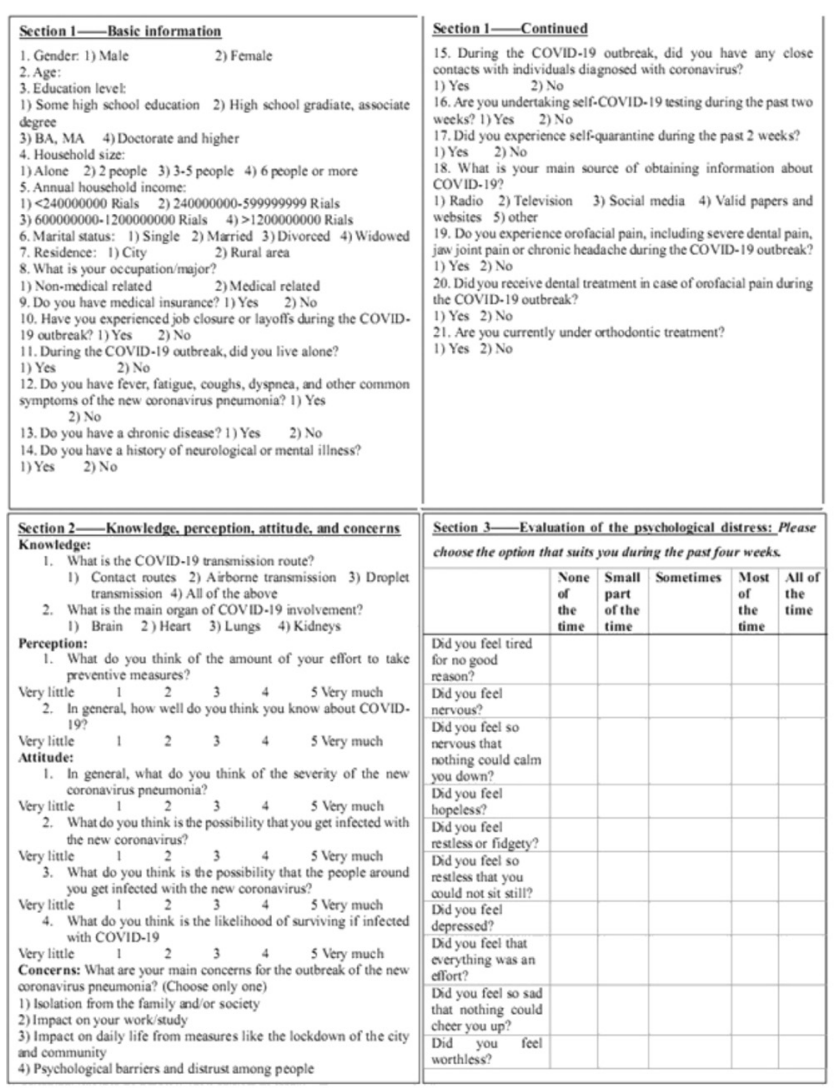

Fig. 1. Questionnaire used in the study, comprising 3 sections
The $2^{\text {nd }}$ part consisted of 9 questions on knowledge (2 multiple-choice questions), perception (2 questions on a 5-point Likert scale; the higher the total score, the higher perception of the participant), attitude (4 questions on a 5 -point Likert scale; the higher the total score, the more negative attitude of the individual), and the main concerns about the influence of the pandemic (a singlechoice question and the participants could choose only 1 option) developed by the investigators.

The validity of the $2^{\text {nd }}$ part of the questionnaire was assessed by submitting the questionnaire to 1 professor in each field - orthodontics, public health and internal medicine. The reliability was assessed by asking 20 subjects to complete it twice with a 2-week interval. Cronbach's $\alpha$ was used as a measure of reliability. All the values were $\geq 0.8$.

The last part of the questionnaire was the Kessler Psychological Distress Scale (K10). ${ }^{21}$ The reliable and valid Persian version of this scale was available at the beginning of the study. ${ }^{22-24}$ There are 10 items (on a 5-point Likert scale) on this scale. The total score was regarded as a continuous variable in this study, with higher scores indicating increased psychological distress. The K10 score is a sensitive screen for diagnosing anxiety and depressive symptoms, with 4 items indicating anxiety (K-anxiety) and 6 items indicating symptoms of depression (K-depression). ${ }^{25,26}$ A total score of $10-19$ is considered normal, while 20-50 indicates mental distress (20-24: mild disorder; 25-29: moderate disorder; 30-50: severe disorder). ${ }^{27}$

\section{Data collection}

The questionnaires were developed at www.docs. google.com and filled in through an online survey. The questionnaires were available from April 25, 2020 to May 20, 2020; during that period, all routine elective medical and dental procedures were suspended except for emergencies.

The questionnaires with missing data or identical answers in all the K10 questions, or with extreme variations in answers regarding similar questions were excluded.

\section{Statistical analysis}

The data was imported to IBM SPSS Statistics for Windows, v. 21.0 (IBM Corp., Armonk, USA). The scores referring to the K10 questions were summed separately to form individual K10 scale, K10-anxiety and K10-depression scores for each respondent. The scores of knowledge, perception and attitude were summed separately to achieve the knowledge scores, the perception scores and the attitude scores, respectively. All the statistical analyses were performed with a two-tailed $\alpha$ significance level of 0.05 , and $95 \%$ confidence interval (CI) for $\beta$ and $p$-value was calculated. 
All the background variables except for age were compared between the groups with the use of the $X^{2}$ test. Age as well as the knowledge, perception and attitude scores were compared between the 2 groups with Student's $t$ test. The primary concerns were compared between the groups by means of the $\chi^{2}$ test.

Regardless of the group, the correlation of age and the knowledge, perception and attitude scores with the Kessler scores was determined using Pearson's correlation test. A comparison of the Kessler scores between various concern choices was evaluated using the one-way analysis of variance
(ANOVA) and the post-hoc Šidák test. The Kessler scores were also compared between genders with Student's $t$ test.

The one-way analysis of covariance (ANCOVA) was conducted to determine differences between the groups in the $\mathrm{K} 10$ scale, $\mathrm{K}$-anxiety and $\mathrm{K}$-depression scores, controlling for the possible confounding variables. The percentages of individuals with mental distress were also compared between the groups by means of the $\chi^{2}$ test. Also, in group 2, one-way ANCOVA was used to compare the Kessler scores in the respondents who "sought pain management" and those who did not.

Table 1. Comparison of the background variables between the study groups

\begin{tabular}{|c|c|c|c|}
\hline Background variables & $\begin{array}{l}\text { Group } 1 \\
n=112\end{array}$ & $\begin{array}{l}\text { Group } 2 \\
n=397\end{array}$ & $p$-value \\
\hline $\begin{array}{l}\text { Gender } n(\%) \\
\text { male } \\
\text { female }\end{array}$ & $\begin{array}{l}23(20.54) \\
89(79.46)\end{array}$ & $\begin{array}{l}100(25.19) \\
297(78.81)\end{array}$ & 0.310 \\
\hline Age [years] $M \pm S D$ & $28.33 \pm 6.03$ & $28.46 \pm 5.90$ & 0.832 \\
\hline $\begin{array}{l}\text { Education } n(\%) \\
\text { some high school education } \\
\text { high school graduate, associate degree } \\
\text { bachelor's/master's degree } \\
\text { doctorate and higher }\end{array}$ & $\begin{array}{c}3(2.68) \\
12(10.71) \\
57(50.89) \\
40(35.71)\end{array}$ & $\begin{array}{c}10(2.52) \\
45(11.34) \\
160(40.30) \\
182(45.84)\end{array}$ & 0.225 \\
\hline $\begin{array}{l}\text { Household size } n(\%) \\
\text { alone } \\
2 \text { people } \\
3-5 \text { people } \\
6 \text { people or more }\end{array}$ & $\begin{array}{c}1(0.89) \\
21(18.75) \\
78(69.64) \\
12(10.71)\end{array}$ & $\begin{array}{c}12(3.02) \\
59(14.86) \\
280(70.52) \\
46(11.59)\end{array}$ & 0.483 \\
\hline $\begin{array}{l}\text { Annual household income [rials] } n(\%) \\
<240,000,000 \\
240,000,000-599,999,999 \\
600,000,000-1,200,000,000 \\
>1,200,000,000\end{array}$ & $\begin{array}{l}11(9.82) \\
36(32.14) \\
44(39.29) \\
21(18.75)\end{array}$ & $\begin{array}{l}43(10.83) \\
124(31.23) \\
104(26.20) \\
126(31.74)\end{array}$ & $0.016^{*}$ \\
\hline $\begin{array}{l}\text { Marital status } n(\%) \\
\text { single } \\
\text { married } \\
\text { divorced } \\
\text { widowed }\end{array}$ & $\begin{array}{c}71(63.39) \\
41(36.61) \\
0(0) \\
0(0)\end{array}$ & $\begin{array}{c}270(68.01) \\
124(31.23) \\
3(0.76) \\
0(0)\end{array}$ & 0.386 \\
\hline $\begin{array}{l}\text { Residence } n(\%) \\
\text { city } \\
\text { rural }\end{array}$ & $\begin{array}{c}108(96.43) \\
4(3.57)\end{array}$ & $\begin{array}{c}385 \text { (96.98) } \\
12(3.02)\end{array}$ & 0.661 \\
\hline $\begin{array}{l}\text { Occupation } n(\%) \\
\text { medical-related } \\
\text { non-medical-related }\end{array}$ & $\begin{array}{l}61(54.46) \\
51(45.54)\end{array}$ & $\begin{array}{l}251(63.22) \\
146(36.78)\end{array}$ & 0.093 \\
\hline Medical insurance $n(\%)$ & $77(68.75)$ & 265 (66.75) & 0.691 \\
\hline Experience of job closure/layoffs $n(\%)$ & $76(67.86)$ & $275(69.27)$ & 0.775 \\
\hline Living alone during the pandemic $n(\%)$ & $12(10.71)$ & $44(11.08)$ & 0.912 \\
\hline History of pneumonia-like symptoms $n(\%)$ & $3(2.68)$ & $5(1.26)$ & 0.286 \\
\hline Close contact with individuals diagnosed with coronavirus $n(\%)$ & $17(15.18)$ & $38(9.57)$ & 0.091 \\
\hline Undertaking self-COVID-19-testing during the past 2 weeks $n(\%)$ & $5(4.46)$ & $20(5.04)$ & 0.804 \\
\hline Self-quarantine during the past 2 weeks $n(\%)$ & $68(60.71)$ & $253(63.73)$ & 0.559 \\
\hline $\begin{array}{l}\text { Main source of obtaining information about COVID-19 n (\%) } \\
\text { radio } \\
\text { television } \\
\text { social media } \\
\text { valid papers and websites } \\
\text { other }\end{array}$ & $\begin{array}{c}0(0) \\
27(24.11) \\
59(52.68) \\
21(18.75) \\
5(4.46)\end{array}$ & $\begin{array}{c}2(0.50) \\
93(23.43) \\
212(53.40) \\
81(20.40) \\
9(2.27)\end{array}$ & 0.691 \\
\hline
\end{tabular}

Group 1 - patients with orofacial pain (OFP); group 2 - the general population; $M$ - mean; SD - standard deviation; COVID-19 - coronavirus disease 2019;

* statistically significant. For all the background variables, the $p$-value was calculated with the $x^{2}$ test except for age (Student's $t$ test). 


\section{Results}

The number of eligible patients in group 1 was 197 . Temporomandibular disorders were present in 92 subjects (87 subjects with TMD of muscle origin, 5 subjects with TMD of joint origin). Headache was present in 84 subjects (53 subjects with headache of chronic tension type, 21 with chronic migraine and 10 with chronic daily headache). The remaining eligible 21 subjects had trigeminal neuralgia (15 subjects) and traumatic neuroma (6 subjects). Twenty-seven subjects with OFP did not fill the questionnaire (response rate: 86.3\%). Totally, 635 respondents were recruited (group 1 or patients with OFP: $n=170$; group 2 or the general population: $n=465)$. Respondents who met the exclusion criteria, or provided incomplete or mixed data were excluded (126 individuals). Finally, 509 eligible respondents (group 1: $n=112$; and group 2: $n=397$ ) underwent the statistical analysis.

\section{Comparison of independent variables between the groups}

Table 1 presents the demographic data and the background variables which were compared between the groups. The household income variable was statistically different between the study groups $(p=0.016)$.

The knowledge, perception and attitude scores of the respondents were not significantly different between the study groups $(p>0.05)$ (Table 2$)$. The concerns of the respondents were not different between the study groups $(p>0.05)$. The most often reported main concern for both groups was "impact on work/studies" (Table 2).

\section{Relationship between psychological indices and the respondents' age, knowledge, perception, attitude, and main concerns, regardless of the group}

Age had a weak inverse correlation with the K10 scale $(r=-0.118 ; p=0.003)$, K-anxiety $(r=-0.114 ; p=0.004)$ and K-depression scores $(r=-0.116 ; p=0.003)$.

Attitude had a moderate positive correlation with the K10 scale $(r=+0.226 ; p=0.0001)$, K-anxiety $(r=+0.215$; $p=0.0001)$ and K-depression scores $(r=+0.224$; $p=0.0001)$. Perception had a weak negative correlation with the K10 scale $(r=-0.108 ; p=0.005)$, K-anxiety $(r=-0.103 ; p=0.008)$ and K-depression scores $(r=-0.106$; $p=0.006)$. Knowledge had a weak positive correlation with the K-anxiety score $(r=+0.077 ; p=0.046)$, while it was not statistically correlated with the K10 scale and K-depression scores $(p>0.05)$.

The K10 scale, K-anxiety and K-depression scores were not statistically different between the respondents with different concerns except for the respondents who chose "psychological barriers and distrust";
Table 2. Comparison of knowledge, perception, attitude, and various concerns between the study groups

\begin{tabular}{|l|c|c|c|}
\multicolumn{1}{|c|}{ Variables } & $\begin{array}{c}\text { Group 1 } \\
n=112\end{array}$ & $\begin{array}{c}\text { Group 2 } \\
n=397\end{array}$ & $p$-value \\
\hline $\begin{array}{l}\text { Knowledge } \\
M \pm S D\end{array}$ & $7.71 \pm 1.24$ & $7.59 \pm 1.43$ & 0.411 \\
$\begin{array}{l}\text { Perception } \\
M \pm S D\end{array}$ & $12.24 \pm 2.94$ & $11.91 \pm 2.63$ & 0.283 \\
$\begin{array}{l}\text { Attitude } \\
M \pm S D\end{array}$ & $1.88 \pm 0.32$ & $1.89 \pm 0.31$ & 0.821 \\
$\begin{array}{l}\text { Concern } n \text { (\%) } \\
\text { isolation from family/society }\end{array}$ & $12(10.71)$ & $58(14.61)$ & \\
$\quad \begin{array}{l}\text { impact on work/studies } \\
\text { impact on daily life }\end{array}$ & $52(46.43)$ & $151(38.04)$ & 0.373 \\
psychological barrier and distrust & $15(13.39)$ & $66(16.62)$ & \\
\hline
\end{tabular}

* statistically significant. For all the variables, the $p$-value was calculated with Student's $t$ test except for concern ( $x^{2}$ test).

they exhibited significantly higher K10 scale ( $p=0.018)$, K-anxiety $(p=0.045)$ and K-depression $(p=0.014)$ scores as compared to the respondents with the primary concern of "isolation from family/society".

\section{Comparison of psychological indices between genders and the groups, and within the groups}

Regardless of the respondents' group, females exhibited significantly higher $\mathrm{K} 10$ scale, K-anxiety and K-depression scores than males $(p=0.002, p=0.002$ and $p=0.003$, respectively).

A one-way ANCOVA was conducted to determine statistically significant differences between the groups in terms of the K10 scale, K-anxiety and K-depression scores, controlling for the household income. The K10 scale, K-anxiety and K-depression scores were significantly higher in group 1 than in group $2(p=0.0001$; $\left.F_{\mathrm{K} 10}=18.31 ; F_{\mathrm{K} \text {-anxiety }}=16.06 ; F_{\mathrm{K} \text {-depression }}=18.29\right)($ Fig. 2$)$.

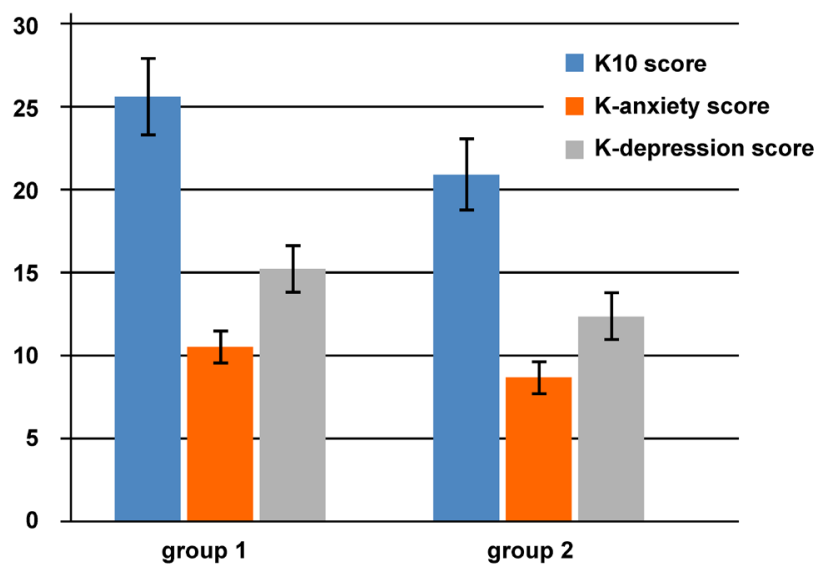

Fig. 2. Comparison of the adjusted psychological indices $(M \pm S D)$ between the study groups

K10 - Kessler Psychological Distress Scale; K-anxiety score - Kessler anxiety score; K-depression score - Kessler depression score. 
Group 1 exhibited a significantly higher percentage of individuals with mental distress than group $2(p=0.047)$ (Fig. 3).

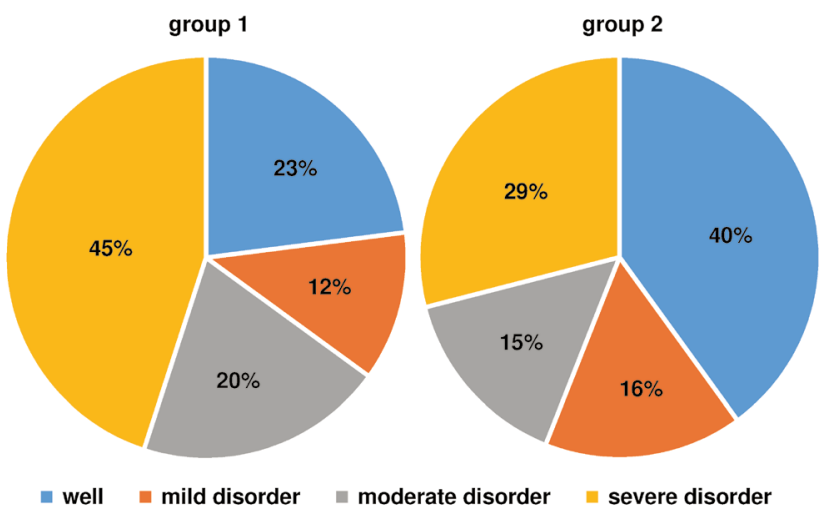

Fig. 3. Comparison of the frequency [\%] of psychological distress between the study groups

In group $1,10.71 \%(n=12)$ of the respondents sought pain management; they did not differ from the respondents in their group who did not seek treatment in terms of the K10 scale and K-anxiety and K-depression scores $(p>0.05)$.

\section{Discussion}

The COVID-19 pandemic has imposed a substantial psychological burden on the world population, especially at the beginning of the outbreak, when individuals encountered unexpected quarantine, unemployment and uncertainty associated with the outbreak. ${ }^{7}$ Pandemicassociated psychological factors might even exacerbate OFP. ${ }^{19}$ The treatment outcome of OFP can also be influenced by depressive symptoms. ${ }^{13}$ Therefore, the early identification of the populations in the first stages of a psychological crisis would allow for the efficient implementation of interventional strategies. ${ }^{3}$ This study analyzed anxiety and depression in 509 respondents, with 397 normal population individuals and 112 patients with OFP, during the COVID-19 pandemic. The factors associated with COVID-19-related psychological distress which were determined in previous studies ${ }^{28-30}$ were evaluated in our study. If they were different between the groups, they were adjusted not to affect the final comparison of the psychological status of the groups. Respondents with chronic illnesses and orthodontic treatment, or oral and maxillofacial surgeries were excluded, as these factors have been reported to affect the psychological condition. ${ }^{31,32}$ In the present study, as the index of the psychological status, the Kessler Psychological Distress Scale was adopted ${ }^{21}$; it was previously used to assess the association between psychological distress and different types of pain, including musculoskeletal pain ${ }^{33}$ and all types of chronic pain. ${ }^{34}$
Our socio-demographic data suggests that females experienced a more significant psychological impact of the outbreak, and had higher levels of anxiety and symptoms of depression. This finding corresponds to a previous extensive epidemiological study, which found that women were at higher risk of depression. ${ }^{28}$ A study on Iranian medical students similarly revealed that anxiety was more prevalent in females than males; however, the study showed no significant difference between genders in depression. ${ }^{35}$ This contrast can be attributed to the fact that medical students respond differently to the pandemicrelated psychological burden as compared to the general population. As previously reported in another research, ${ }^{30}$ older individuals exhibited less psychological distress in the present study, although the correlation was weak.

High levels of knowledge (score: $1.88-1.89$ out of 2 ) and perception (score: 7.59-7.80 out of 10) in both groups represents success with regard to awareness measures and information programs. Higher knowledge of COVID-19 was associated with higher anxiety in the present study. It has been suggested that a higher level of information about COVID-19 received from various sources or the excessive use of media reporting on COVID-19 predict more anxiety among individuals, ${ }^{36,37}$ which confirms our results. However, higher perception and a more positive attitude were found to be related to lower psychological distress. Previously, similarly to our findings, higher cognitive perception of the COVID-19 risk was reported to be related to a lower risk of depression for people in public health crises. ${ }^{38}$ Another study revealed that regardless of the actual amount of knowledge individuals had, those perceiving themselves as more knowledgeable exhibited a stronger sense of control and experienced more happiness during the outbreak. ${ }^{39}$

Moreover, our findings are consistent with the positive correlation between attitude and psychological quality of life assessed in previous studies, in which the higher the coping attitude about the disease was, the higher the score in the psychological domain was obtained. ${ }^{40,41}$ Keeping in mind the knowledge-attitude-behavior theory, there is a complex interaction between knowledge, perception and attitude. ${ }^{42}$ Therefore, during the COVID-19 pandemic, all these variables should be addressed and improved concomitantly to enhance the related psychological status.

As for the main concerns about COVID-19, objective choices, like the impact on work/studies and daily life, were more important, while more subjective ones were relatively less important, such as the isolation from the family/society, psychological barriers and distrust among people. The main concern for individuals with OFP as well as for the general population was "impact on work/ studies".

The respondents who chose "psychological barriers and distrust" as the primary concern exhibited significantly higher psychological distress than the respondents with the primary concern of "isolation from family/society". 
This is somehow justified by the results of a study on adults indicating that some cognitive strategies, such as rumination, catastrophizing and self-blame, are linked to poorer psychological well-being. ${ }^{43}$ In contrast, other strategies, like positive refocusing, putting into perspective and acceptance, show few significant associations with poorer psychological health. ${ }^{43}$

The main results of the present study indicated that the $\mathrm{K} 10$ scale, K-anxiety and K-depression scores were noticeably higher in participants with OFP than in the other group. The frequency of mental distress was higher in the OFP group.

This higher level of anxiety and depressive symptoms in individuals with OFP suggests that people with a history of pain experience would be possibly the main targets of psychiatric assessment and care. In a recent systematic review there was consistent evidence that chronic pain was associated with PTSD, ${ }^{44}$ which confirms our results. Previously, OFP, especially chronic pain, was associated with lower oral health-related quality of life, higher suicidal ideation, depression, anxiety, PTSD, and psychological distress signs. ${ }^{13,18,44}$ The comparison of the limited number of population-based studies is difficult due to different psychological indices and methods used. ${ }^{45-48}$ None of the previous studies assessed the psychological status of patients with OFP in comparison with the general population after the psychological effect of an accident. However, our results are similar to those reported by Kindler et al., concerning psychological distress, and specifically the role of anxiety and depression related to pain; the authors found a moderate-to-strong relationship between the symptoms of depression or anxiety and the signs of TMD. ${ }^{46}$ Also, Natu et al. stated that the severity of TMD had some bearing on the quality of life, emotional states and sleep quality. ${ }^{47}$ Dindo et al. suggested that psychological inflexibility was related to the expression of the symptoms of anxiety and depression in adults with migraine ${ }^{48}$ The results of a recent study by Simoen et al. before the pandemic indicated that patients with pain attributed to TMD had higher depression and anxiety scores in comparison with the general population. ${ }^{49}$ Although different psychological indices were applied (Patient Health Questionnaire-9 and Generalized Anxiety Disorder-7), their findings were similar to ours during the pandemic. ${ }^{49}$ A recent study showed that the aggravation of the psychoemotional status caused by the COVID-19 pandemic could result in the exacerbation of bruxism and TMD symptoms, and even lead to increased OFP..$^{20}$

When people with chronic pain are denied assessment and treatment, their condition can worsen significantly, decreasing health-related quality of life, increasing pain and exacerbating depression. ${ }^{50,51}$ Efforts are suggested to prevent and control pain - particularly chronic pain - during the COVID-19 pandemic. Moreover, addressing emergencies associated with pain, avoiding medication shortages due to panic-buying and avoiding the inaccessibility of the remaining healthcare options during movement restrictions are recommended, and pain management providers face the challenge of delivering face-to-face services through different modes..$^{52}$

Most patients with OFP did not seek dental/medical pain management during the pandemic. A study suggested that precautionary measures, such as avoiding sharing utensils, hand hygiene and wearing masks to prevent the spread of COVID-19, could have had protective psychological effects during the early stages of the pandemic. ${ }^{28}$ Therefore, it might be concluded that the process of diagnosis and treatment of patients can be resumed with appropriate preventive measures so that they are not afraid of referring for pain management.

Overall, social media were the primary health information channels in both groups during the COVID-19 pandemic. Similarly to our findings, other studies reported that participants usually obtained information about the novel coronavirus through social media. ${ }^{53,54}$ It should be noted that this large platform should be used for raising awareness and training in high-risk groups in the coronavirus pandemic, and the content of health information provided during the pandemic should be based on evidence to avoid adverse psychological reactions. ${ }^{28}$ On the other hand, this familiarity of the population with social media can be taken as an advantage. Telehealth, the sourcing of treatment modalities by means of digital and telecommunication technologies, can be provided by health professionals to exchange information necessary for self-care as well as the diagnosis, treatment and prevention of pathologies and injuries, including OFP or psychological distress. ${ }^{55}$

Varying degrees of the outbreak severity, national economy, government preparedness, the availability of medical supplies/facilities, a proper dissemination of COVIDrelated information, and cultural differences have led to regional differences in the general public's psychological health during the pandemic. ${ }^{7}$ The COVID-19 outbreak began in Iran on February 19, 2020, and promptly spread all over the country. On April 21, 2020, of 330,137 tested patients, 80,868 were infected with COVID-19 (55,987 recovered, 3,513 became critically ill and 5,031 died). Like everywhere in the world, the formal announcement of the outbreak resulted in public panic and anxiety. Fake news and misinformation further increased public anxiety. The Headquarter for Coronavirus Combat and Prevention implemented strategies, such as stopping mass gatherings, the closure of educational institutes, national coordination with volunteer, civilian and military forces, the national screening program, and social distancing. These measures potently alleviated some of the public fear. However, at the same time, they could affect the economy. People were urged to strongly avoid familial gatherings and trips during the New Year holidays. Stricter measures, especially travel bans, were introduced on March 26,2020 . The measures desirably lead to the flattening 
of the epidemic curve. ${ }^{56}$ In the subsequent months, the government gained control of the virus and began relaxing lockdown measures. At the beginning of June 2020, the media reported a worrying sharp increase in the number of COVID-19 cases that mirrored March peak levels: 3,574 new infections in $24 \mathrm{~h}$ as of June $3 .{ }^{57}$

This is the first report on the psychological distress of individuals with OFP as compared to the general population during the COVID-19 pandemic, to the best of our knowledge. The main strengths of the present investigation are the comparison of the severity of this psychological distress and a considerable number of participants.

Like other questionnaire-based research, the accuracy of our study results depended on the participants' accuracy in answering the questionnaire. Our respondents were mostly females and were of the young adult group. Due to ethical requirements concerning anonymity and confidentiality, we were not allowed to collect contact details and personal information from the respondents. As a result, we could not conduct a prospective study that would provide concrete evidence to support the need for a focused public health initiative. Given the limited resources available and the time-sensitivity of the COVID-19 outbreak, we adopted the non-randomized, convenient sampling strategy. Due to the cross-sectional design, the associations in the study cannot be perceived as causal. Lastly, this study had some limitations in interpreting the results, since COVID-19 is a novel coronavirus disease and limited research is available for comparison.

Future studies on a comparable number of males and females within various age groups are suggested. Furthermore, it would be ideal to conduct a prospective study on the same group of participants after some time, especially when all routine dental and medical procedures, including elective ones, are allowed. Future studies with a similar examination approach in a population-based group and a patient group are recommended to draw more logical conclusions.

\section{Conclusions}

In summary, our findings suggested that during the rapid rise of the COVID-19 outbreak, the psychological status was associated with knowledge, perception, attitude, and concerns about COVID-19. Females suffered more from psychological distress than males. As compared to the general population, psychological distress, and symptoms of depression and anxiety were noticeably higher in individuals with OFP, who suffered from moderate psychological distress.

\section{ORCID iDs}

Maryam Saki (D) https://orcid.org/0000-0003-3085-2127 Maryam Shadmanpour (D) https://orcid.org/0000-0002-8220-3885 Hooman Zarif Najafi (D) https://orcid.org/0000-0002-1516-8880

\section{References}

1. Liu $Y$, Yan $L M$, Wan $L$, et al. Viral dynamics in mild and severe cases of COVID-19. Lancet Infect Dis. 2020;20(6):656-657. doi:10.1016/ S1473-3099(20)30232-2

2. Adhikari SP, Meng S, Wu YJ, et al. Epidemiology, causes, clinical manifestation and diagnosis, prevention and control of coronavirus disease (COVID-19) during the early outbreak period: A scoping review. Infect Dis Poverty. 2020;9(1):29. doi:10.1186/s40249-020-00646-x

3. Qiu J, Shen B, Zhao M, Wang Z, Xie B, Xu Y. A nationwide survey of psychological distress among Chinese people in the COVID19 epidemic: Implications and policy recommendations. Gen Psychiatr. 2020;33(2):e100213. doi:10.1136/gpsych-2020-100213

4. Xiang YT, Yang Y, Li W, et al. Timely mental health care for the 2019 novel coronavirus outbreak is urgently needed. Lancet Psychiatry. 2020;7(3):228-229. doi:10.1016/S2215-0366(20)30046-8

5. Brooks SK, Webster RK, Smith LE, et al. The psychological impact of quarantine and how to reduce it: Rapid review of the evidence. Lancet. 2020;395(10227):912-920 doi:10.1016/S0140-6736(20)30460-8

6. Van Bortel T, Basnayake A, Wurie F. Psychosocial effects of an Ebola outbreak at individual, community and international levels. Bull World Health Organ. 2016;94(3):210-214. doi:10.2471/BLT.15.158543

7. Xiong J, Lipsitz O, Nasri F, et al. Impact of COVID-19 pandemic on mental health in the general population: A systematic review. J Affect Disord. 2020;277:55-64. doi:10.1016/j.jad.2020.08.001

8. Montazeri A, Tavousi M, Rakhshani F, et al. Health Literacy for Iranian Adults (HELIA): Development and psychometric properties. Payesh. 2014;13(5):589-599. http://payeshjournal.ir/article-1-279-en.html. Accessed September 1, 2020.

9. Häggman-Henrikson B, Liv $P$, Ilgunas A, et al. Increasing gender differences in the prevalence and chronification of orofacial pain in the population. Pain. 2020;161(8):1768-1775. doi:10.1097/j. pain.0000000000001872

10. Ananthan S, Benoliel R. Chronic orofacial pain. J Neural Transm (Vienna). 2020;127(4):575-588. doi:10.1007/s00702-020-02157-3

11. Durham J, Shen J, Breckons $M$, et al. Healthcare cost and impact of persistent orofacial pain: The DEEP study cohort. J Dent Res. 2016;95(10):1147-1154. doi:10.1177\%2F0022034516648088

12. Durham J. Orofacial pain: Care pathways, consequences and costs. Oral Surg. 2020;13(4):307-308. doi:10.1111/ors.12550

13. Bäck K, Hakeberg M, Wide U, Hange D, Dahlström L. Orofacial pain and its relationship with oral health-related quality of life and psychological distress in middle-aged women. Acta Odontol Scand. 2020;78(1):74-80. doi:10.1080/00016357.2019.1661512

14. Lee LTK, Yeung RWK, Wong MCM, McMillan AS. Diagnostic subtypes, psychological distress and psychosocial dysfunction in southern Chinese people with temporomandibular disorders. JOral Rehabil. 2008;35(3):184-190. doi:10.1111/j.1365-2842.2007.01792.x

15. Sipilä K, Ylöstalo PV, Joukamaa M, Knuuttila ML. Comorbidity between facial pain, widespread pain, and depressive symptoms in young adults. J Orofac Pain. 2006;20(1):24-30.

16. Yap AUJ, Dworkin SF, Chua EK, List T, Tan KBC, Tan HH. Prevalence of temporomandibular disorder subtypes, psychologic distress, and psychosocial dysfunction in Asian patients. J Orofac Pain. 2003;17(1):21-28.

17. Burke ALJ, Mathias JL, Denson LA. Psychological functioning of people living with chronic pain: A meta-analytic review. $\mathrm{Br} J \mathrm{Clin}$ Psychol. 2015;54(3):345-360. doi:10.1111/bjc.12078

18. Sherman JJ, Carlson CR, Wilson JF, Okeson JP, McCubbin JA. Posttraumatic stress disorder among patients with orofacial pain. J Orofac Pain. 2005;19(4):309-317.

19. Almeida-Leite CM, Stuginski-Barbosa J, Rodrigues Conti PC. How psychosocial and economic impacts of COVID-19 pandemic can interfere on bruxism and temporomandibular disorders? J Appl Oral Sci. 2020;28:e20200263. doi:10.1590/1678-7757-2020-0263

20. Emodi-Perlman A, Eli I, Smardz J, et al. Temporomandibular disorders and bruxism outbreak as a possible factor of orofacial pain worsening during the COVID-19 pandemic - concomitant research in two countries. J Clin Med. 2020;9(10):3250. doi:10.3390/jcm9103250

21. Andrews $G$, Slade T. Interpreting scores on the Kessler Psychological Distress Scale (K10). Aust N Z J Public Health. 2001;25(6):494-497. doi:10.1111/j.1467-842X.2001.tb00310.x 
22. Dadfar M, Lester D, Atef Vahid MK, Esfahani MN. The psychometric parameters of the Farsi form of the Kessler Psychological Distress Scale (K10) in psychiatric outpatients. Int J Med Res Health Sci. 2016;5(2):1-7. https://www.ijmrhs.com/medical-research/the-psychometric-parameters-of-the-farsi-form-of-the-kessler-psychological-distress-scalek10-in-psychiatric-outpatients.pdf. Accessed September 1, 2020.

23. Atef Vahid M, Dadfar M, Kessler RC, Bahrami F, Lester D. Validation of Farsi version of the Kessler Psychological Distress scale (K10) in college students. Eur J Soc Sci. 2015;49(1):115-124.

24. Dadfar M, Atef Vahid MK, Lester D, Bahrami F. Kessler Psychological Distress Scale (K6): Psychometric testing of the Farsi form in psychiatric outpatients. Adv Biores. 2016;7(2):105-108. doi:10.15515/abr.0976-4585.7.2.105108

25. Furukawa TA, Kessler RC, Slade T, Andrews G. The performance of the $\mathrm{K} 6$ and $\mathrm{K} 10$ screening scales for psychological distress in the Australian National Survey of Mental Health and Well-Being. Psychol Med. 2003;33(2):357-362. doi:10.1017/s0033291702006700

26. Brooks RT, Beard J, Steel Z. Factor structure and interpretation of the K10. Psychol Assess. 2006;18(1):62-70. doi:10.1037/1040-3590.18.1.62

27. Rural and Regional Health and Aged Care Services Division. Victorian Population Health Survey 2001. Selected Findings. Melbourne, Australia: Victorian Government Department of Human Services; 2002;1:29-31.

28. Wang C, Pan R, Wan X, et al. Immediate psychological responses and associated factors during the initial stage of the 2019 coronavirus disease (COVID-19) epidemic among the general population in China. Int J Environ Res Public Health. 2020;17(5):1729. doi:10.3390/ijerph17051729

29. Zhong BL, Luo W, Li HM, et al. Knowledge, attitudes, and practices towards COVID-19 among Chinese residents during the rapid rise period of the COVID-19 outbreak: A quick online cross-sectional survey. Int J Biol Sci. 2020;16(10):1745-1752. doi:10.7150/ijbs.45221

30. Wang C, Pan R, Wan X, et al. A longitudinal study on the mental health of general population during the COVID-19 epidemic in China. Brain Behav Immun. 2020;87:40-48. doi:10.1016/j.bbi.2020.04.028

31. Jung $\mathrm{MH}$. Quality of life and self-esteem of female orthognathic surgery patients. J Oral Maxillofac Surg. 2016;74(6):1240.e1-e7. doi:10.1016/j.joms.2016.01.046

32. Johal A, Alyaqoobi I, Patel R, Cox S. The impact of orthodontic treatment on quality of life and self-esteem in adult patients. Eur J Orthod. 2014;37(3):233-237. doi:10.1093/ejo/cju047

33. Reme SE, Dennerlein JT, Hashimoto D, Sorensen G. Musculoskeletal pain and psychological distress in hospital patient care workers J Occup Rehabil. 2012;22(4):503-510. doi:10.1007/s10926-012-9361-5

34. Shipton E, Ponnamperuma D, Wells E, Trewin B. Demographic characteristics, psychosocial measures, and pain in a sample of patients with persistent pain referred to a New Zealand tertiary pain medicine center. Pain Medicine. 2013;14(7):1101-1107. doi:10.1111/pme.12113

35. Nakhostin-Ansari A, Sherafati A, Aghajani F, Khonji MS, Aghajani R, Shahmansouri N. Depression and anxiety among Iranian medical students during COVID-19 pandemic. Iran J Psychiatry. 2020;15(3):228-235. doi:10.18502/ijps.v15i3.3815

36. Malesza M, Kaczmarek MC. Predictors of anxiety during the COVID-19 pandemic in Poland. Pers Individ Dif. 2021;170:110419. doi:10.1016/j.paid.2020.110419

37. Nekliudov NA, Blyuss O, Cheung KY, et al. Excessive media consumption about COVID-19 is associated with increased state anxiety: Outcomes of a large online survey in Russia. J Med Internet Res. 2020;22(9):e20955. doi:10.2196/20955

38. Ding Y, Xu J, Huang S, Li P, Lu C, Xie S. Risk perception and depression in public health crises: Evidence from the COVID-19 crisis in China. Int J Environ Res Public Health. 2020;17(16):5728. doi:10.3390/ ijerph17165728

39. Yang $\mathrm{H}, \mathrm{Ma}$ J. How an epidemic outbreak impacts happiness: Factors that worsen (vs. protect) emotional well-being during the coronavirus pandemic. Psychiatry Res. 2020;289:113045. doi:10.1016/j.psychres.2020.113045

40. Campos de Sousa M, Dias FA, Nascimento JS, Dos Santos Tavares DM. Correlation of quality of life with knowledge and attitude of diabetic elderly. Invest Educ Enferm. 2016;34(1):180-188. doi:10.17533/udea.iee.v34n1a20
41. Imtiaz A, Hasan E, Hossain MA, Khan NM. Attitudes toward COVID19 among young adults: Role of psychological distress. 2020. doi:10.31234/osf.io/futpk

42. Schrader P, Lawless KA. The knowledge, attitudes \& behaviors approach how to evaluate performance and learning in complex environments. Perform Improv. 2004;43(9):8-15. doi:10.1002/pfi.4140430905

43. Balzarotti S, Biassoni F, Villani D, Prunas A, Velotti P. Individual differences in cognitive emotion regulation: Implications for subjective and psychological well-being. J Happiness Stud. 2016;17(1):125-143. doi:10.1007/s10902-014-9587-3

44. Fishbain DA, Pulikal A, Lewis JE, Gao J. Chronic pain types differ in their reported prevalence of post-traumatic stress disorder (PTSD) and there is consistent evidence that chronic pain is associated with PTSD: An evidence-based structured systematic review. Pain Med. 2017;18(4):711-735. doi:10.1093/pm/pnw065

45. Bertoli $\mathrm{E}$, de Leeuw R. Prevalence of suicidal ideation, depression, and anxiety in chronic temporomandibular disorder patients. J Oral Facial Pain Headache. 2016;30(4):296-301. doi:10.11607/ofph.1675

46. Kindler S, Samietz S, Houshmand M, et al. Depressive and anxiety symptoms as risk factors for temporomandibular joint pain: A prospective cohort study in the general population. J Pain. 2012;13(12):1188-1197. doi:10.1016/j.jpain.2012.09.004

47. Natu VP, Yap AUJ, Su MH, Irfan Ali NM, Ansari A. Temporomandibular disorder symptoms and their association with quality of life, emotional states and sleep quality in South-East Asian youths. J Oral Rehabil. 2018;45(10):756-763. doi:10.1111/joor.12692

48. Dindo L, Brandt CP, Fiedorowicz J. Cross-sectional relations between psychological inflexibility and symptoms of depression and anxiety among adults reporting migraines or risk factors for cardiovascular disease. J Contextual Behav Sci. 2019;13:1-6. doi:10.1016/j.jcbs.2019.06.001

49. Simoen L, Van den Berghe L, Jacquet W, Marks L. Depression and anxiety levels in patients with temporomandibular disorders: Comparison with the general population. Clin Oral Investig. 2020;24(11):3939-3945. doi:10.1007/s00784-020-03260-1

50. Lynch ME, Campbell F, Clark AJ, et al. A systematic review of the effect of waiting for treatment for chronic pain. Pain. 2008;136(1-2):97-116. doi:10.1016/j.pain.2007.06.018

51. Choinière $M$, Dion $D$, Peng $P$, et al. The Canadian STOP-PAIN project - Part 1: Who are the patients on the waitlists of multidisciplinary pain treatment facilities? Can J Anesth. 2010;57(6):539-548. doi:10.1007/s12630-010-9305-5

52. Eccleston C, Blyth FM, Dear BF, et al. Managing patients with chronic pain during the COVID-19 outbreak: Considerations for the rapid introduction of remotely supported (eHealth) pain management services. Pain. 2020;161(5):889-893. doi:10.1097/j. pain.0000000000001885

53. Huynh G, Han Nguyen TN, Tran VK, Vo KN, Vo VT, Pham LA. Knowledge and attitude toward COVID-19 among healthcare workers at District 2 Hospital, Ho Chi Minh City. Asian Pac J Trop Med. 2020;13(6):260-265. doi:10.4103/1995-7645.280396

54. Bhagavathula AS, Aldhaleei WA, Rahmani J, Mahabadi MA, Bandari DK. Knowledge and perceptions of COVID-19 among health care workers: Cross-sectional study. JMIR Public Health Surveill. 2020;6(2):e19160. doi:10.2196/19160

55. Fioratti I, Reiss FF, Fernandes LG, Saragiotto BT. The COVID-19 pandemic and the regulations of remote attendance in Brazil: New opportunities for people dealing with chronic pain. BrJP. 2020;3(2):193-194. doi:10.5935/2595-0118.20200039

56. Salimi R, Gomar R, Heshmati B. The COVID-19 outbreak in Iran. J Glob Health. 2020;10(1):010365. doi:10.7189/jogh.10.010365

57. Venkatesan P. COVID-19 in Iran: Round 2. Lancet Infect Dis 2020;20(7):784. doi:10.1016/S1473-3099(20)30500-4 